\title{
CA \\ Performative Data: Cultures of Government Data Practice
}

\author{
Morgan Currie and W. F. Umi Hsu
}

08.13 .19

Peer-Reviewed By: Anon.

Clusters: Data

Article DOI: $10.22148 / 16.045$

Journal ISSN: 2371-4549

Cite: Morgan Currie and W. F. Umi Hsu, "Performative Data: Cultures of Government Data Practice," Journal of Cultural Analytics. August 13, 2019.

Most of the current academic literature on open data looks outward at the data's reuse by the public. This article describes, rather, the cultural practice of open data inside city governments. Hand-in-hand with the launch of open data policies, city governments have embraced data analytics to track performance, set goals, justify budget expenditures, direct public services, and represent their work to the public. Through an increased need to data-fy, or to transform records or actions into digital data, staff considers the analytical possibilities of existing administrative records both as economic evidence of government activities and as reusable assets with statistical and machine-actionable functions. These data practices provide a legitimized way for municipal governments to know and govern the city and manage its resources. Contended as performative acts, local governments' data practices help the city perform aspects of its functions and values such accountability, transparency, and democracy.

For evidence of this shift, the authors draw on an in-depth empirical study of Los Angeles's open data program from 2013 to 2018. This research entailed participant observations, field visits, and interviews with city staff to describe the largely 
invisible cultural processes and technical work that produce and use Los Angeles's administrative datasets. To analyze these observations, the authors describe three aspects of the datafication of records as they unfolded in the Department of Cultural Affairs: 1) the work of producing economic data to evaluate government program output and perform effective usage and investment of government resources; 2) the practice of aggregating and mapping programmatic data with community wellbeing indicators to identify gaps in services and enact equity; 3 ) the engagement with members of the public using government data to spur dialogs and ideas and demonstrate the democratic value of participation in collaboratively designing a service delivery ecosystem. The article contributes to the much-needed understanding of how governments are adapting managerial, analytic, and public engagement practices in an increasingly data-driven society.

\section{Introduction: Quantifying Culture}

Quantifying arts and culture became a heralded concept in the last century, when, as early as 1967, futurist and businessman Alvin Toffler recommended a "cultural data system" to undergird policy-making and to understand the impacts of a booming post-industrial arts sector. ${ }^{1}$ The rise of the arts index, however, is largely a $21^{\text {st }}$ century phenomenon. North American urban policy scholar Maria Rosaria Jackson proposed the use of data to measure cultural vitality in 2006, thus inspiring a number of municipal and state level cultural data collection and metrics efforts involving cultural indicators. ${ }^{2}$ Indexes used to quantify arts impact, including the economic effects of cultural support and so-called "creative classes," have since been on the rise. ${ }^{3}$ These indexes largely import ideas from the field of management studies to gauge the "performance" of a country's or municipality's cultural sector by gathering metrics on economic and administrative goals such as high audience participation, financial support, and increased market share. ${ }^{4}$ The U.S. non-profit DataArts, for instance, began collecting longitudinal metrics on non-profit cultural organizations in cities in 2004, while another U.S.-based non-profit, Americans for the Arts, initiated

\footnotetext{
${ }^{1}$ Toffler, Alvin. "The Art of Measuring the Arts," The Annals of the American Academy of Political and Social Science 373, no. 1 (September 1, 1967): 141-55.

${ }^{2}$ Maria Rosario Jackson, Florence Kabwasa-Green, and Joaquin Herraz, "Cultural Vitality in Communities: Interpretation and Indicators," The Urban Institute, 2006.

${ }^{3}$ Brendan Rawson, John Kreidler, and Philip J. Trounstine, Creative Community Index [Silicon Valley, 2002 and 2005]. Ann Arbor, MI: Inter-university Consortium for Political and Social Research [distributor], 2015-05-27. https://doi.org/10.3886/ICPSR35580.v1

${ }^{4}$ Kushner and Cohen, 2017. For instance, the U.S. National Arts Index drew on Robert Kaplan and David Norton's Balanced Scorecard model, which emphasized a business's financial success, internal processes, learning and growth, and customer satisfaction.
} 
its National Arts Index project in 2010, using 81 variables to capture arts and culture vitality between 1998 and 2013. ${ }^{5}$ The trend continues outside the U.S; for instance, the United Kingdoms' Arts Index has tracked arts-based variables at global scales since 2007..$^{6}$ UNESCO's framework for cultural statistics links the cultural sector with a nation's economic development and captured international data from 2009 and 2013 on cultural heritage sites, visual arts, performance, and the creative services. ${ }^{7}$

While most of these indexes are conducted at the national level, municipal arts agencies influenced by open data and evidence-based policymaking have also begun to approach their services in terms of data: number of public artworks, attendance at live performances, amount of grants funding, or the location of arts centers. This shift puts city-level cultural affairs agencies on track to undertake quantitative and geospatial analyses of their services. These methods may be familiar to other departments, such as Engineering, Planning, or Transportation, but are not the traditional approach for agencies that fund and support the cultural arts. Writing back in the 60s, Toffler complained that staff at arts institutions came mostly from artistic, rather than administrative, backgrounds; for these organizers, counting occurrences was not the way to evaluate the quality of a city's cultural life because a city's qualitative experience of its arts and culture could not be measured. Indeed, what the quantification of culture attempts to capture are phenomena that city agencies traditionally evaluate as experiential, interpretive, subjective dimensions of a city's cultural life. Shared cultural codes, variances in aesthetic expressions and practices, and intricacies of the experiential dimension of arts and culture generally defy quantification. Toffler, however, was prescient ${ }^{8}$ - over the past two decades cities have warmed to the concept of 'evidence-based policy making' in all corners.

This article analyses a shift in bureaucratic cultures within one city arts agency as it adopted processes of quantification and datafication to assess the efficiency and impact of its services. To describe this shift in finer detail, we draw from participant observations at the City of Los Angeles Department of Cultural Affairs (DCA) from 2014-2018. The first author volunteered in the department for six months from April to October 2016. The second author is a staff member lead-

\footnotetext{
${ }^{5}$ Roland J. Kushner, and Randy Cohen, "Creating a Policy Index for the Arts (SSIR)," Stanford Social Innovation Review, Fall 2017, 48-53.

${ }^{6}$ Retrieved November 14, 2018 from http://forthearts.org.uk/publications/arts-index-20072016/

${ }^{7}$ Retrieved November 14, 2018 from http://en.unesco.org/creativity/

${ }^{8}$ Toffler, however, wanted to devise quality indicators that tried to measure such phenomena as 'sophistication of audience,' 'appearance of genius' and number of 'works of excellence'-criteria that now would be seen as largely cultural constructs that are too laden with contestable class and sociopolitical values to have much meaning.
} 
ing design strategy and data initiatives at the DCA and has been a participant observer at the agency since 2013. This paper also draws on interviews by the first author conducted with 33 city staff members as well as the Mayor's office.

We frame the analysis of fieldwork and interview data through linguistics and cultural theory; drawing on this set of literature we theorise the performativity of data in shaping the bureaucratic culture of this city department. Through an analysis of the case study, we find that datafication encourages a shift towards economisation of cultural data, new forms of citizen participation that give rise to data publics, and a geospatial understanding of equitable access to city services through the visual and statistical identification of 'arts deserts'. To begin, however, we will describe the recent trends of datafication among city governments as a historical context of our theorisation on data performativity.

\section{Datafication in City Government}

Datafication within government is in no way a novelty. Historians Ted Porter, Alain Desrosieres, and Patricia Cline Cohen have all described in rich detail the link between democratic governance and quantified information collected about populations on their health, housing, work, and education. ${ }^{9}$ What we note, however, is the acceleration of new practices of datafication in city agencies that have appeared since the mid-2000s. The Open Data initiative started by U.S. President Barack Obama in 2006, for instance, launched a world-wide trend for governments to release vast troves of machine-readable, standardized data into the public sphere. ${ }^{10}$ Cities have also turned to existing databases and documents to discover what can be newly rendered as value-added secondary data, often to measure agency performance, determine service allocation, or make predictions about housing conditions or crime. According to a 2018 Pew Foundation report, "states have begun harnessing existing information through data analytics-procedures that review data to identify meaningful information and correlations," ${ }^{11}$ in addition to collecting statistical records for the express purpose of

\footnotetext{
${ }^{9}$ Theodore M. Porter, Trust in Numbers, Reprint edition (Princeton University Press, 1996); Alain Desrosières, The Politics of Large Numbers: A History of Statistical Reasoning (Cambridge: Harvard University Press, 2002); Patricia Cline Cohen, A Calculating People: The Spread of Numeracy in Early America (Psychology Press, 1999).

${ }^{10}$ The White House, Office of the Press Secretary, 'Executive Order-Making Open and Machine Readable the New Default for Government Information', Whitehouse.Gov, 2013 [accessed 12 October 2016]

${ }^{11}$ Sallyann Bergh, Alyssa Davis, Amber Ivey, Dan Kitson, and Jennifer Thornton, "How States Use Data to Inform Decisions," The Pew Charitable Trusts, February 2018, p. 1. Emphasis by the authors.
} 
quantification, as states have done throughout the 20th century. ${ }^{12}$ In this regard, governments are following other industries, such as commercial bibliographic systems and open science data repositories, that have long tapped economic and social value in public records by creating secondary statistical objects. Similar to these "big data" systems in science and industry, datafication in government finds new value from aggregating records of cases filed and completed, permits approved, financial transactions made, even stray animals processed. These data lead to additional functionality when they are fed into algorithms that drive city services, from trash pick-up to policing to child services. ${ }^{13}$

To further tap into this secondary value, digital records that automate decisionmaking may be structured for multiple stakeholders and technical platforms beyond the databases they were designed for, for instance as part of open data portals or sharing contracts with private companies such as Google and Waze, the GPS navigation app. ${ }^{14}$ Certain types of bureaucratic agencies are accustomed to multi-purposing their own data-particularly in engineering and transportation departments, which have long collected data and integrated them into electronic territorial maps or dashboards. These practices by departments that were not accustomed to sharing data with external platforms have ramped up in the last decade. For instance, the City of San Francisco worked with Yelp to create a format for accessing public restaurant health scores that Yelp publishes on its restaurant pages. ${ }^{15}$

The datafication of city government is not only a technical but also a cultural shift in how staff comes to understand urban processes as solvable through data. Jose van Dijck calls this epistemological shift dataism, or 'big data thinking' that relies on "the objective quantification and potential tracking of all kinds of human behavior and sociality." ${ }^{16}$ City governments, however, primarily track services and infrastructure, not social activities. Yet a belief in data as a powerful solution to problems of service logistics and public infrastructure drives many cities' administrative process. Los Angeles Mayor Garcetti evoked this line of thinking at a civic tech event in 2014: "Can an app or an algorithm help traffic move more quickly, for instance through traffic light sensors? Can we revitalize Holly-

\footnotetext{
${ }^{12}$ Sallyann Bergh, Alyssa Davis, Amber Ivey, Dan Kitson, and Jennifer Thornton. "How States Use Data to Inform Decisions," The Pew Charitable Trusts, February 2018, p. 1. Emphasis by the authors.

${ }^{13}$ Virginia Eubanks, Automating Inequality: How High-Tech Tools Profile, Police, and Punish the Poor (St. Martin's Press, 2018).

${ }^{14}$ Bradley, R. (2015, June 2). Waze and the Traffic Panopticon. Retrieved November 14, 2018, from http://www.newyorker.com/business/currency/waze-and-the-traffic-panopticon.

${ }^{15}$ Local Inspector Value-Entry Specification. Yelp.com. Retrieved November 14, 2018, from https: //www.yelp.com/healthscores.

${ }^{16}$ Jose van Dijck, "Datafication, Dataism and Dataveillance: Big Data between Scientific Paradigm and Ideology," Surveillance \& Society, 12 (2014), 197-208
} 
wood through an innovative app that will help people find a way to park, through a mesh network of real time parking information?"17 Public servants proclaim data to play a powerful role in managing complex urban systems.

Consequently, staff saw city data as wielding a certain form of epistemic power: The power of records is traditionally indexical and evidentiary; the U.S., for instance, defines a record as any recorded information made by a Federal agency, and it acts as official evidence of a government action, grounding legal and policy claims. ${ }^{18}$ The power of data, on the other hand, can include these uses but also those of statistical analysis, mapping, visualization, and algorithmic processing. From this perspective, the indexicality and provenance of a record-reflecting its original context as part of past government activities ${ }^{19}$ - becomes less a matter of focus than creating secondary data with operational functionalities that can help manage the city through numbers and graphs.

As a result, the role played by new data analytic services is symbolically quite large, since it taps directly into the broader imaginary about big data-sending a message that public service delivery can be imagined more effectively and equitably. Many city staff members we spoke to saw public data as an at-hand asset from which new civic or monetary value can be extracted at little cost. According to an employee in the mayor's office, for instance, in the old paradigm, the lifecycle of information is "valuable, then tapers down after use... to a plain old toothbrush toothpaste commodity." With new data practices, information instead is "something that produces increased efficiency. Something to figure out is: What's the highest value in-house to look at?" 20 This technocultural shift in how departments understand and use their information products has begun to reshape department roles and instigate new institutional practices.

Many scholars have pointed out the work of data to produce, as much as represent, phenomena. ${ }^{21}$ As we discuss next, we consider this force of data its performative dimension. This transformative power of data affects accounting routines, provides new modes of engagement with the public, and shapes the design of city

\footnotetext{
${ }^{17}$ Quoted at Tech LA, May 31, 2014.

${ }^{18} 44$ U.S. Code $\$ 3301$-Definition of records

${ }^{19}$ Anne J. Gilliland-Swetland, Enduring Paradigm, New Opportunities: The Value of the Archival Perspective in the Digital Environment. CLIR, February 2000. Available online at http://www.clir.org/pubs/abstract/pub89abst.html.

${ }^{20}$ Interview conducted February 27, 2014.

${ }^{21}$ Theodore M. Porter, Trust in Numbers: The Pursuit of Objectivity in Science and Public Life (Princeton University Press, 1996); Lisa Gitelman, ed. Raw Data Is an Oxymoron (MIT Press, 2013); Geoffrey C. Bowker, and Susan Leigh Star, Sorting Things Out: Classification and Its Consequences (MIT Press, 2000); Alain Desrosières, The Politics of Large Numbers: A History of Statistical Reasoning (Harvard University Press, 2002); Bruno Latour, Science in Action: How to Follow Scientists and Engineers Through Society (Harvard University Press, 1987).
} 
services. In the next section, we theorize the performative function of data, before providing the case study of the Los Angeles Department of Cultural Affairs.

\section{The Performativity of Data}

To describe the performative dimensions of data, we turn to J. L. Austin's classic linguistic theory. In his work How to Do Things with Words, Austin observes the transformative and productive power of speech acts beyond describing reality. He terms constative speech to describe factually based speech acts, which are typically evaluated for how well they represent what they aim to portray. He uses the term performative to refer to speech acts that perform an action, such as promising or declaring ("I swear I won't do that again," "I now pronounce you husband and wife"). Performative sentences not only describe reality but change it in the act of an utterance. Such sentences are neither true nor false but have force in the world beyond their ability to represent. ${ }^{22}$ Many scholars have taken the idea of performativity beyond its linguistic context to describe the performativity of other phenomena, including the reproduction of gender over time through the historical practice and institutionalization of the "stylization of the body." ${ }^{23}$

For our purposes, we apply the concept of performativity to data. In "A Sociology of Numbers", Espeland and Stevens take a similar approach, pointing out that numerical quantification is not only an act of representing the empirical accuracy of a phenomenon. Quantification also has a force to call new things and categories into being, to signal institutional legitimacy, and to shape the distribution of power and resources. Numbers can alter the very things they purport to represent; ${ }^{24}$ for instance, Donald Mackenzie describes how economic models do not simply express price patterns that were already existing, but actively change them. ${ }^{25}$ Data also perform to the extent that they produce as much as they portray subjects and objects. Rita Raley points out the performative consequences of the data by-products of search engine browsing: for some, "the composition of flecks and bits of data into a profile of a terror suspect, the re-grounding of abstract data in the targeting of an actual life, will have the effect of producing that

\footnotetext{
${ }^{22}$ John L. Austin, and John Langshaw Austin. How to Do Things with Words (Harvard University Press, 1975).

${ }^{23}$ Judith Butler, Gender Trouble: Feminism and the Subversion of Identity (Routledge, 2006).

${ }^{24}$ Wendy Nelson Espeland, and Mitchell L. Stevens, "A Sociology of Quantification*," European Journal of Sociology / Archives Européennes de Sociologie 49, no. 3 (December 2008): 401-36.

${ }^{25}$ Donald Mackenzie, 'Is Economics Performative? Option Theory and the Construction of Derivatives Markets', Journal of the History of Economic Thought, 28 (2006), 29-55
} 
life, that body, as a terror suspect." ${ }^{26}$ In contexts of surveillance, the mass collection and processing of data about people can produce the idea of a person as a suspect such that their statistical profile comes to stand in for the actual person. ${ }^{27}$

This 'reactivity' of data to intervene in the social world can be seen when data transform the amorphous complexity of phenomena into stable categoriesgiving rise to many sociological concepts we now take for granted such as 'unemployment, 'IQ', and 'public opinion'; ${ }^{28}$ as we show in our case study, data give rise to new concepts-the notions of 'arts deserts' and 'arts oases'-that have subsequent effect on City policy. Beyond creating categories, standardizing numerical data can subject phenomena to measurement and comparability and to predictions and monitoring. These treatments of data can help determine the distribution of resources and power. In the case study below, we detail how administrative data make departmental activities visible and measurable, and hence subject to decisions and policies around funding and service goals.

Data's power of producing opportunities for actions can lead to organizational and cultural change. Scholars have written about the force of data to transform bureaucratic cultures. Fiore-Silfvast and Neff, for instance, write about the "social performance of data" in the context of medical records, where data sometimes "come to represent a notion of actionability", of change based on supportive evidence. ${ }^{29}$ Here data play a legitimating function because of how they are thought of culturally-their 'social valences' as Fiore-Silfvast and Neff put itthe association of data with efficiency, objectivity, and accountability primarily within private sector accounting practices. In a similar example, Michael Power describes the performative role of audits. Here, official ideals about the potential of audits to create efficient, accountable, and cost-effective institutions have force. In this way audits are not simply descriptive "but performative, projecting and enacting ideals of their capability which legitimate the field of knowledge as a whole." ${ }^{30}$ Managerial conceptions of accountability mean that simply enacting a certain style of administration can confer legitimacy, irrespective of practical results. Similarly, as we show, in city government agencies, datafication promises a business intelligence of administration that encourages growth and efficiency; it also calls on agencies to enact a more collaborative notion of governance by

\footnotetext{
${ }^{26}$ Rita Raley, "Dataveillence and Countrveillence," In The World of Indicators, edited by Richard Rottenburg, 34-55 (Cambridge University Press, 2015), p. 121-146.

${ }^{27}$ Matzner, Tobias. "Beyond Data as Representation: The Performativity of Big Data in Surveillance," Surveillance \& Society; Newcastle upon Tyne 14, no. 2 (2016): 197-210.

${ }^{28}$ Espeland and Stevens, 2008.

${ }^{29}$ Fiore-Silfvast, Brittany, and Gina Neff, "What We Talk about When We Talk Data: Valences and the Social Performance of Multiple Metrics in Digital Health," Ethnographic Praxis in Industry Conference Proceedings 2013, no. 1 (n.d.): 74-87, p. 74.

${ }^{30}$ Michael Power, The Audit Society: Rituals of Verification (OUP Oxford, 1999), 9.
} 
engaging with what Ruppert calls "data publics". ${ }^{11}$

All of these types of data performativity-the production, analysis, and tracking of data objects and subjects and the enactment of bureaucratic legitimacy through datafication-are non-representational effects of data with transformative force. When a department represents its work through data-through maps, metrics, and digitised objects-this constitutes the social and technical practices that in turn substantiate its status and institution as a bureaucracy. In city agencies, datafication creates new processes of resource allocation, new relations between governed and governors, and generates new objects that affect the distribution of public goods. "Data are deeds" that act on the very things they quantify. ${ }^{32}$ In the next section we introduce the Department of Cultural Affairs (DCA) before describing in greater detail how these performative data practices evolve at DCA.

\section{The Culture of Bureaucracy in Los Angeles: The Case of Cultural Affairs}

In 2014 Los Angeles Mayor Eric Garcetti used his third executive directive in office to mandate departmental participation in the city's open data portal. ${ }^{33}$ The policy required departments to publish useful datasets on a public portal and to begin submitting metrics gauging their municipal performance to the Mayor's Office (metrics that could also be published as open data). The open data initiative was one dimension of a larger plan to bring city government more in line with the technology industries that had begun to dominate twenty-first century economies, especially as Silicon Valley cast its shadow over the U.S. west coast.

One outcome of these policies is that their implementation revealed highly uneven data cultures across city departments. As departments enacted the policies, some underwent more "data frictions", a term we borrow from Paul Edwards to describe "the great difficulty, cost, and slow speed of gathering large numbers of records in one place in a form suitable for massive calculation." ${ }^{34}$ There were

\footnotetext{
${ }^{31}$ Evelyn Ruppert, "Doing the Transparent State: Open Government Data as Performance Indicators," in A World of Indicators: The Making of Governmental Knowledge through Quantification, edited by R. Rottenburg, S. E. Merry, S.-J. Park, and J. Mugler (Cambridge: Cambridge University Press, 2015), 127-50.

${ }^{32}$ Espeland and Stevens, 2008, 431.

${ }^{33}$ Garcetti, Eric, 'Executive Directive No. 3', Office of Los Angeles Mayor Eric Garcetti, 2013. Retrieved November 14, 2018 from http://www.lamayor.org/garcetti_directs_city_departments_to_ collect_data_for_open_data_initiative.

${ }^{34}$ Paul N. Edwards, A Vast Machine: Computer Models, Climate Data, and the Politics of Global
} 
sharp differences across city department as new data policies met the on-theground material realities of existing resources differently dispersed across the city.

The Department of Cultural Affairs (DCA) experienced more data frictions than was the norm across other departments. DCA maintains a wealth of records on its three programmatic areas: Grants Administration Division supporting artists and non-profit arts organizations; its Percent for Art Public Art programs, which set aside one percent of costs of any development project in the city as an investment in the art in the public realm; and community art centers and theaters embedded throughout neighborhoods to deliver arts education, exhibitions, festivals, and performing arts events. At the start of this research project, little of this data was stored electronically and organized centrally. The department is small relative to others in the city and has no dedicated IT staff. Said the DCA data coordinator in 2016:

We don't have the time and resources to digitize our data. Most of what we have exists within semi-analog systems. Some parts are in paper form, nonsearchable PDFs; other records are stored in disparate spreadsheets. Our workflow involves lots of wrangling and transmissions of government memorandums as PDFs. Sometimes it's hard to see the organizational and transmission paths of our data. Not all of us know the structure of the filing cabinets and digital file directories on the intranet that are meant to store our records. The arts sector in the US is under-resourced. Like other arts agencies, we don't have the resources to rebuild or update our filing and data systems. We're just pulling records as needed. ${ }^{35}$

Our liaison there told us that rethinking services in terms of statistical measurements and outputs was challenging. The department had not been accustomed to thinking of its work solely in terms of quantitative measurement. The question of defining a metric that would not reduce the quality of art experience, which is primarily social, emotional, and cultural, had been a topic of conversation among staff. This question led to further discussion regarding the appropriate methods of capturing evaluative metrics that ascertain the relationship between arts access to and community well-being.

In contrast, data friction occurred less in departments that already produced public machine-readable data. The Bureau of Engineering (BoE), for instance, has been handling machine-readable geographic data since becoming one of the first customers of ESRI, the most widely used GIS software, in the mid 1980s. BoE is a

Warming (Mit Press, 2010), 90.

${ }^{35}$ Interview conducted on February 22, 2016. 
large, resource-rich, technocratic haven where dense, customized electronic systems for internal and public use are the standard; it is responsible for providing an accurate record of all the land activities that occur within the city, providing the legal basis for the formation of boundaries and locations of public and private properties. The records are kept in an internal electronic database and are also accessible to the public on a dynamic web map of 527 layers of data (not all of which comes from Engineering). In addition to the ESRI-based map, the department also maintains an electronic vault of all past permits and an electronic permit filing system.

Because of this robust legacy system of public, machine-readable data, the new data policy presented a minimal burden for BoE. The department already had staff devoted to maintaining and circulating electronic records internally and to the public. The staff members I spoke with, for instance, were enthusiastic about open data. The department's principal civil engineer told me, "I was supportive of [open data], because we've always had that general mindset anyway." 36 Data publishing was already a default mode of the department.

DCA's differences from BoE illustrate the degree to which datafication relies on an existing bedrock of information infrastructures: not only robust electronic records systems but also platforms for public data access. When the Mayor's Office launched the open data executive directive, DCA had few modern data practices in place and no dedicated data staff to enact it. In contrast, as a lucrative agency that brings in money to the city through permit fees, BoE has the means to build customizable databases and websites, and it retains ownership of all of its data. As a result, the Mayor's data policies made little operational difference to the Department of Engineering.

The performativity of datafication at BoE was still in play as the new data policies affected BoE's view on the affordances of its records. The City's new data policies exemplified a shift in how BoE staff considered data from the data's original indexicality towards circulation and reuse. One engineer I spoke now saw BoE's records in relation to new data publics; he speculated on how the open data's release might inspire people to build applications with BoE data:

Now by putting it out there in an open format, sure, we're inviting other people to look at that same data differently, present it differently, create new tools. I mean, who knows? There may be supplements to NavigateLA that they can say, 'Hey, we've developed this cool module for you, and we'll give it to you guys free to make NavigateLA that much better." 37

\footnotetext{
${ }^{36}$ Interview conducted August 15, 2014.

${ }^{37}$ Interview conducted August 15, 2014.
} 
While datafication subtly transformed BoE's views of its record practices, but litthe else, the effect on DCA was much starker. In part because DCA had to create new digital systems to respond to the Mayor's data policies, rather than tying existing systems to the new demands, DCA has embraced datafication more fully and resourcefully than many other departments in the city. In the next three sections we outline cultural and technical shifts that have taken place in DCA over the four years since the department started enacting new data practices and policies. These changes include economising, building data publics, and creating a new method to identify 'arts deserts' and 'arts oases' to guide equity-based programming and policy-making. In each instance, we discuss how data perform by creating new quantitative objects used to evaluate the department, shape its policies, and interact with the public.

\section{Economizing}

In 2014, as a part of the Mayor's Executive Directive No. 3, the Mayor's Office asked all departments to establish and report performance metrics related to their service goals and to publish these metrics on the open data portal soon after the website's launch. In addition to the web portal, the Mayor's Office created a dashboard for citizens and residents to see recent counts on housing permits issued, numbers of police officers on force, number of lane miles paved, and percentage of graffiti cleaned within 48 hours. The dashboard demonstrates whether or not the metric achieves the goal set through a color scheme-green for above the goal and red for below. ${ }^{38}$

By quantifying features of their services and evaluating these service outputs against related resources in numerical terms, staff members come to see the work they do through an economic lens. Quantification is seen, that is, to have a future impact on how they operate and on budgets. As Kurunmaki et al. define it, such metrics play a role in economizing governments: in constituting departments as economic entities that must often compete for limited resources. ${ }^{39}$ To demonstrate effectiveness, departments must tie their work to economic concepts such as cost efficiency and return on investment-to whether the money allocated and spent has yielded calculable results. Economizing follows the logic of New Public Management, a style of administration from the 1980s that requires departments to justify their budgets and salaries based on output measures-on actual pro-

\footnotetext{
${ }^{38}$ Retrieved on November 14, 2018, http://dashboard.lamayor.org

${ }^{39}$ Liisa Kurunmäki, Andrea Mennicken, and Peter Miller, "Quantifying, Economising, and Marketising: Democratising the Social Sphere?" Sociologie Du Travail 58, no. 4 (October 1, 2016): 390402.
} 
grammatic performance-rather than pre-set rules and standards or based on the institutional knowledge of experts. NPM is meant to create a culture of selfmanagement that is more federalized than top-down: each agency sets its own explicit, measurable performance standards to demonstrate the effectiveness of its service delivery. ${ }^{40}$ Taking a similar approach, managerial staff in the City of Los Angeles often described data as a resource of economic and institutional capital that may create cost efficiencies. Said an employee from the Mayor's Office,

It's a time of less resources. We're never going to get pre-2008, prebubble staffing levels, so now it's finding out how to do things better and easier, but the old ways and old silos of structures of government that had been built in LA [are] cumbersome . . . so we're hoping this [open data] can unlock ideas between general managers and how the city runs. ${ }^{41}$

The economization practice can encourage city staff to work across the bureaucratic silos. However, this management style can also create a culture that privileges public services that produce easily measurable output, such as graffiti removal and trash pickup.

Within DCA specifically, the new policy has led, in consequence, to the economization of cultural data. Performance management turns cultural analytics into transactional data, following in the footsteps of national cultural indexes such as DataArts, which helps arts organizations build funding profiles, and National Center for Arts Research, whose Vibrancy Index measures "vibrancy" in terms of market share and supply and demand. To comply with the performance management directive, DCA turned to available and quantifiable output data such as the number of participants and activities at DCA Community Arts and Performing Arts programs, the number of non-profit arts organizations and individual artists receiving grants from the department, and the amount of grants and corporate donations raised. ${ }^{42}$ Since 2015, DCA's data staff worked to establish a broader and detailed metric model with the input of each of the department's various division directors, such that the data definition is supported and informed by their understanding of divisional goals. The exercise demonstrated the need to update and digitize the systems that catalog DCA's programmatic efforts-for instance, databases of records of organizational and artist grantees and arts class registration-as well as the enormous effort of collecting, standardizing, and centralizing

\footnotetext{
${ }^{40}$ Hood, Christopher, "The 'New Public Management' in the 1980s: Variations on a Theme," Accounting, Organizations and Society 20, no. 2 (February 1, 1995): 93-109.

${ }^{41}$ Interview conducted February 27, 2014.

${ }^{42} \mathrm{https} / /$ data.lacity.org/A-Livable-and-Sustainable-City/Cultural-Affairs-PerformanceMetrics/e3gp-gx53
} 
these records.

Data work has ultimately played a role in causing DCA to re-evaluate its recordskeeping processes, some of which are now articulated in terms of standardized statistical outcomes and goals. At the same time, data work has introduce new modes of internal governance and oversight driven by considerations of economic efficiency and staff capacity. Said DCA's data coordinator, "We want to make sure our programmatic output reflects a need of investment in the area. It's [...] about sustaining the organization through an economic lens." ${ }^{33}$ These accounting practices have the effect of changing DCA's practices to the extent that staff strives to maintain or improve these indicators, giving these numberswhich only count what is countable, and not the unquantifiable effects of DCA service such as quality of service-a degree of control over shaping DCA work. As such, "measures become aspirations," and numbers that initially are created to depict wind up disciplining. ${ }^{44}$

Quantifying programmatic numbers also means the development of a standard, discrete unit that cuts across different types of programmatic work. This data standardization practice reduces arts experiences into economic units that can only represent one particular dimension of the service; it turns arts services into a product with an ascribed market value poised for economic examinations such as cost-benefit analysis. This practice of commensuration, collapsing different qualities into a common unit for the sake of comparison, ${ }^{45}$ takes the value of service experience out of the social and cultural context intended in the program. For example, with the intention to meet the needs and interests of each neighborhood, Community Arts programs are designed with varying qualities, such as depth of engagement and choices in artistic discipline, aesthetic approaches, and cultural subject matters; these choices are relevant to the community's concerns in a given time. The design of programs is also intentional in terms of quantity, frequency and duration of engagement. To serve neighborhoods with families and youth, for instance, arts classes are offered two to three times a week to young students. These students receive up six hours of arts classes, each season for 10 weeks. A continual engagement is critical to the learning and developmental goals, especially for youth who lack social or economic stability in other areas of life. These highly scaffolded educational interactions are forced into units that are commensurate with other types of lighter-touch arts programming for adults and professionals, such as public programs that accompany a contemporary art

\footnotetext{
${ }^{43}$ Interview conducted September 8, 2017.

${ }^{44}$ Espeland and Stevens, 2008, 416.

${ }^{45}$ Alexander Styhre, "The Economic Valuation and Commensuration of Cultural Resources: Financing and Monitoring the Swedish Culture Sector," Valuation Studies, No. 1(1) 2013: 51-81. DOI 10.3384/vs.2001-5992.1131151
} 
gallery exhibition in the format of a singular artist talk or an annual day-long musical festival that draws more than 20,000 audience members. These "apples-tooranges" comparisons can be even more jarring if cultural analytics were placed side by side with metrics from other, non-cultural public service contexts, such as voter registration drives or drought management educational sessions.

The numerical output unit of an "arts event or activity" removes the depth of content and audience appropriateness, stripping the data from the context of its programmatic cycle. In aggregated form, these output numbers form a cost analysis that represents the City's "return on investment" in the arts and culture. Reducing the value of arts experience to a transactional representation is a logical administrative response to policies under the NPM mindset. This representation is demonstrative of the City's cost-effectiveness in delivering its services to constituents. The effect of this type of data performativity will be seen in the way it reconfigures, rather than simply represents, the department's activities and services.

\section{Geographic Equity and "Arts Deserts"}

Government datasets appeal to their proponents as sources of objectivity, a derivative of bureaucratic systems divorced from subjective insights under the sway of political motivations, conscious or not. ${ }^{46}$ Indeed, staff members we spoke to view their data as a source of legitimacy and accountability that justifies the allocation of public resources. According to a staff member in the Mayor's Office: "

A lot of times political problems can be challenged and questioned... If we do data-driven decision-making, we can take the politics out of decision-making and be more responsive to the public good and public demands versus if we don't." 47

That data can create a neutral ground for consensus formation with the public is a very common perspective among staff we spoke with. Governing through numbers can demonstrate public responsibility through rationalization; it follows in the sociological tradition of subjecting problems of governance to statistical methods to render the state "knowable." ${ }^{48}$ By simplifying complexity and following collectively established procedures, these authoritative methods have

\footnotetext{
${ }^{46}$ Desrosieres, 2002. Porter, 1996.

${ }^{47}$ Interview conducted February 8, 2016.

${ }^{48}$ Nikolas Rose and Peter Miller, "Political Power beyond the State: Problematics of Government," The British Journal of Sociology 43, no. 2 (1992): 173-205.
} 
the power to shape and intervene in a governed territory.

Following these sentiments, DCA has recently begun using data to guide and justify its service delivery in a manner that reflects its mission to support and provide access to arts and culture. In early 2018, DCA created a "Neighborhood Arts Profile," a data tool to allow staff to measure cultural vitality in the city's neighborhoods. ${ }^{49}$ The map pinpoints the offices of non-profit organizational recipients of the city's arts and cultural grants programs, locates city-managed theatres and community arts centers, and tracks cultural events and festivals through extracting data from online calendars and web apps of cultural events such as DiscoverLA. The map also puts these cultural programs in visual adjacency to other cultural institutions such as museums, public libraries, historical cultural monuments, as well as in relation to youth and wellbeing indicators, including the California Human Development Index; Census data such as poverty ratio; and the Arts Equity Index, which ranks quality of arts education programs at the local school district.

In addition to mapping the location of arts venues and city-managed cultural infrastructure, DCA began to collect and aggregate cultural activity data to evaluate the event-level cultural vibrancy of different neighborhoods. These cultural events analytics are ranked based on an indexical scoring system informed by the department's mission of access and equity. DCA privileges events that are free or low cost in the ranking system, since the department forward its mission to increase access to the arts. The map also prioritizes events with access points to public and mass transportation. The interactive data map has helped the staff gain access to "fingertip information" about the communities and people the department is serving, bringing together empirical and up-to-date data that can inspire conversations and programmatic decisions toward the department's mission. ${ }^{50}$ The coordinator hopes that by "putting dots on map ... maybe the points will form patterns that can give us basic insights. Is there an area of concentration or scarcity?"51 The project will eventually drive programming with up-to-date geographic and demographic data to show how the multitudinous neighborhoods of the city are evolving, especially as the city faces rapid growth and demographic shifts.

Maps both simplify and select from a complex reality. A visual medium, they surface patterns and can act as evidence; as such, they have the power to sway public opinion and shape the spaces they represent. In a clear example of the performativity of data, the map has produced a newly visualized and soon-to-be

\footnotetext{
${ }^{49}$ Neighborhood Arts Profile. http://neighborhoodartsprofile.org.

${ }^{50}$ Interview conducted September 8, 2017.

${ }^{51}$ Interview conducted September 8, 2017.
} 
calculable phenomenon, the concept of the "arts desert." Arts deserts are the department's term for areas with an impoverished access to publicly available arts and cultural services. After seeing the results of this mapping exercise and reflecting on the spatial and geographical patterns within the public-serving arts delivery ecosystem, department staff derives insights about areas of concentration or scarcity within the City. At a staff meeting, a map of Los Angeles poverty rates was shown in spatial proximity to DCA's community arts facilities. This visual proximity confirmed staff's assumption of need in serving in areas where DCA's arts centers have been established.

Revealing 'arts deserts' (or 'arts oases') provokes administrators to consider service delivery in light of the department's mission to provide geographical equity of arts programming, now made visible on the map. Seeing this delivery pattern within socioeconomic context of each neighbourhood, community indicators of poverty and youth density can further the goal of a place-based equity by motivating staff decisions. Visual abstractions of service needs-the who and where that matters to the agency-can help staff generate a picture of its service goals and advocate for change. This type of data performativity entails the ability for a graphic representation of culture and socioeconomics to surface a new way of looking and thinking that contributes to eventual actions toward the values being represented.

\section{Data Publics and Momentary Civics}

Data practice for DCA is also about two-way exchange. While the city's older public interfaces, such as the BoE's public-facing map, were seen as increasing efficiency and transparency, DCA's approach to datafication also retools democratic engagement in government service design and delivery. The department has instigated a type of civic participation through sourcing data work from community members. Arts data create new visions of the civic subject.

In 2017, the City of Los Angeles and Los Angeles County held an inaugural "Arts Datathon," a public event that invited residents and administrators to explore the region's arts and culture assets through datasets. ${ }^{52}$ In one day, the event drew over 150 participants and crowd-sourced data-informed cultural strategies and programs. Organizers scattered tables with zines entitled "Guide to Spreadsheets for the Spreadsheet-phobic." Arts practitioners, administrators, arts enthusiasts, and data-savvy professionals worked in small groups, each focused on a specific

\footnotetext{
${ }^{52}$ Scott Reed, "Arts Access Datathon Final Report." 2017. Artsdatathon.org. Retrieved November 14, 2018 from http://artsdatathon.org/documentation/final-report/.
} 
topic chosen by the team, from correlating values between a city Displacement Index and a list of non-profit arts organizations, to mapping spatial relationships between independent book stores and Metro transit stops. Participants turned to data to divine how the region's arts ecosystem might be improved by increasing access to arts and culture around a vast, teeming metropolitan area of over 10 million people.

Datathon participants prototyped eleven projects of apps and services built on existing data. Said DCA's data coordinator, the event helped DCA formulate a "data agenda" by "aggregating data, finding data, establishing data relationship with other departments and the County-all of this was able to come together as a by-product of Datathon." 53 As a result of the event, DCA was able to track down data on arts freelancer businesses from the City's Office of Finance and historic preservation data from the Planning Department. In all DCA compiled and presented a list of 33 datasets, which became critical in the department's development of the Neighborhood Arts Profile. ${ }^{54}$

In this instance, arts data perform a new relationship between a public agency and its constituents by calling new civic practices and subjects into being. Through participatory datathon events, DCA instigates citizen collaboration through data work. At the Arts Datathon, staff learned from members of the arts-engaged public about their values and perspectives on arts access; it promoted a hands-on, material form of engagement through data analysis and application programming that took place alongside inquiries, discussions, and deliberation.

Datathons enact momentary civics, in that their publics come together in an extremely short time span for the purpose of collective ideation. These event-based publics are strong but temporary. The experimental ethos, along with the ideas and prototypes generated, however, rarely coalesce into stable long-term organising. These events allow the public to explore and learn about administrative tasks and policy-making - which can potentially improve public understanding of the mechanics of governance; despite that they do not bring about sustained participation in administrative tasks or policy. Through a high concentration of social energy and dialog on civic concerns, these datathon events instead can catalyze or rekindle civic spirit and interests in the public sphere, which, in a time of political apathy and civic stagnation, can be an asset toward augmenting democratic

\footnotetext{
${ }^{53}$ Interview conducted September 8, 2017.

${ }^{54}$ The event also sparked programmatic and strategic conversations between municipal, nonprofit, cultural institutional staff to examine access to the arts by mapping data on City and County data portals. Producing data led to City-County data partnership with a steering committee co-chaired by members of City and County arts agencies and the need for regionwide data governance in Los Angeles. Most recently, the second Arts Datathon led to partnerships with the LA County Public Library and USC Libraries with a focus on improving infrastructure to arts collections data.
} 
participation. This new mode of civic formation exposes the inner workings of government bureaucracy and strives to increase the proximity between local government administration and its constituents through its data. Datafication in city governance can bring about a new mode of ephemeral but energetic democratic involvement. This type of data performativity could have a long-term effect that will take time to unfold within the larger democratic social sphere.

\section{Conclusion}

DCA's new data practices illustrate a noteworthy tension between reductive and more productive uses of data. As noted earlier, datafication manifests differently across departments, depending on available resources and the types of services and programs offered. DCA is a public agency whose services are experiencedriven and less infrastructurally focused. The notion of measuring culture necessarily rules out the intangible qualities of DCA's services. The agency has struggled with counting while staying true to its quality-oriented mission. One DCA staff member said, "So much of the data isn't just fixing a sidewalk and making sure light works, but it's quality of experience, qualities that are social, emotional and cultural. That's the hardest to measure." 55 The removal of cultural data from their experiential and programmatic context and their subsequent recontextualization requires ongoing engineering of methods, systems, and articulations, in order to stay responsive to the city's administrative shift toward workforce efficiency and process automation.

DCA's example offers a nuanced understanding of how data is used and represented, reflecting a host of ideologies common in the public sector in the big data era: private sector models of financial management, scientific reasoning from the sociological traditions, and democratic participation in governance. Each context reveals how data practices evolve flexibly in order to adapt and transform a constellation of organizational and policy agendas that sometimes present contradicting ideologies. For instance, while data quantification serves the purpose of measuring the effectiveness of city resource management, this kind of costbenefit analysis narrows the focus of the department's work to be put in comparison with other city departments in terms of performance measures. This level of analysis can present a tension with the agency's higher mission of equity, as instantiated in the practice of mapping and visualizing publicly available cultural resources. Municipal governments have to strike a delicate balance between cost savings for the sake of business viability and their public mission of providing

\footnotetext{
${ }^{55}$ Interview conducted September 8, 2017.
} 
access to meaningful city services and experiences.

Furthermore, economizing the experience of arts services by assigning numerical values to exhibition or music classes also poses dissonance with the richness and creativity of co-designing the arts ecosystem with members of the public, as in the case of the datathon event. In the former case, data are compared to raw materials representing culture as economic resources that can be expended, consumed, parsed, or substituted for other programmatic services. In the latter case of data collaboration as a form of collective ideation, agencies treat, visualize, and recontextualize data as raw creative materials to co-develop a more accessible arts ecosystem.

The performative framework sets the stage for a critical analysis of data as a cultural practice. Locating this human practice within the environment of government bureaucracy, we hope, has begun to illuminate the cultural logic behind the intricate administrative systems of record keeping, tools, habits, values, and politics. Governments exist in a larger cultural and financial ecology comprised of capital and information flow. Within $21^{\text {st }}$ century manifestation in the United States, data practices are responses to historical shifts in technology, labor, and epistemology. City staff come into this historical moment with various relationships to data depending on their organizational position and mission. These social particularities render the many multidimensional implications of datafication in government.

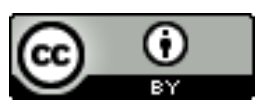

Unless otherwise specified, all work in this journal is licensed under a Creative Commons Attribution 4.0 International License. 